\title{
Impact of urban textures on residential building performances in terms of energy and cost efficiency
}

\author{
Suzi Dilara Mangan ${ }^{1, *}$, Gul Koclar Oral ${ }^{2}$, and Idil Erdemir Kocagil ${ }^{2}$ \\ ${ }^{1}$ Biesterdwarsweg 37, 5615 AK Eindhoven, The Netherlands \\ ${ }^{2}$ Istanbul Technical University, Department of Architecture, 34437 Istanbul, Turkey
}

\begin{abstract}
Rapid urbanization, responsible for considerable global energy consumption, emphasizes sustainability challenges, in particular that of climate change. In order to tackle with climatic and environmental problems, the first step is to achieve energy efficiency in urban textures, are the main source of emissions, the major part of which is due to the energy consumption of buildings. Therefore, this study aims to develop and suggest a model which allows the evaluation of the level of effects of the design parameters which should be considered at the scale of urban textures, on the energy and economic performance of buildings to design sustainable, energy efficient built environments. Energy and economic performances of a reference building mode led in different urban texture alternatives were evaluated. In the first stage, the evaluations regarding energy consumption were performed through DesignBuilder simulation program. In the second stage, for the assessment of economic performance of the alternatives life cycle cost (LCC) analyses were performed integrated to the energy performance analyses. Consequently, the urban texture alternative which achieved the optimum result in terms of energy and cost efficiency was determined for Istanbul representing temperate-humid climatic region where an ongoing mass urban renewal has already been changing the existing urban textures.
\end{abstract}

\section{Introduction}

It is an undeniable fact that energy use in urban areas has increased rapidly with the increase in urban population. In parallel to this, with the current increase in population and urbanisation rate, it is estimated that global urban areas will increase three fold compared to the beginning of the 20th century [1] and two third of the global population will be living in urban areas by 2050 [2]. Deepening concern about fast growth of urban areas, global warming and depletion of fossil fuels entails sustainable energy solutions for urban areas. Therefore, sustainable urban development as part of the sustainability concept is at the top of the agenda of all countries.

In order to identify energy efficient policies and actions to ensure sustainable urban development in urban areas, first existing urban textures should be evaluated. Accordingly, buildings which are responsible for 32 percent of global energy consumption and one fourth of the human induced $\mathrm{CO}_{2}$ emissions globally [4] are critically important. Achieving energy efficiency in buildings in other words improving buildings' energy performance are accepted as one of the fastest and costefficient solutions that can be useful to make a significant reduction in high energy costs, reduce $\mathrm{CO}_{2}$ emissions and boost local economic development. Many studies have demonstrated that the developing stages of design, construction and use of buildings and urban textures with an energy and cost efficient approach will play an important role in creating urban areas that can be sustainable in the long term [5-7].

To describe and model the interaction of the urban texture with the climate and energy, the following parameters should be considered: aspect ratio, street orientation, sky view factor, local and neighborhood scale, street trees and urban parks [8-10]. The most important parameter among those that are considered to define urban textures that affect outdoor comfort conditions based on climatic characteristics is the ratio of average building height $(\mathrm{H})$ to average street width (W). This aspect ratio, which defines the relations among buildings in the sections of urban textures, controls solar access and wind movements with limitations of orientation and causes changes in micro-climate data. Additionally, it can affect comfort conditions of the buildings within an urban texture. Ali-Toudert [11] studied a building in different urban textures and using differing building properties in three climate regions and determined that cooling decreased with deep street canyons. Strømann-Andersen and Sattrup [12] analyzed settlement textures in North Europe to investigate the effects of height-width ratio $(\mathrm{H} / \mathrm{W})$ of urban textures on heating, cooling and lighting energy consumption and concluded that $\mathrm{H} / \mathrm{W}$ ratio had an effect up to $30 \%$ in total energy consumptions.

* Corresponding author: dilaramangan@yahoo.com -currently visiting researcher at the Department of the Built Environment, Eindhoven University of Technology. 
Thus, urban textures which have a complex and dynamic structure and which are not subject to major changes for many years have an undeniable impact on buildings' energy performance and on urban climate. Taking into account only the building scale to design energy and cost efficient buildings or improve energy performance of a building in a cost efficient way would be insufficient. Therefore, suitable methods that evaluate building energy performance in urban textures which differ depending on several design parameters including building form-height, street width, orientation, green areas designs should be used. Studies on design sustainable buildings and urban textures are evaluated in several stages and in the first stage, i.e. design stage building performance can vary significantly depending on the defined parameters.

Together with the new building percentage of over $4 \%$, Turkey grows faster than the EU average which is less than $1 \%$ [13]. Turkey's fast growing and evolving building stock leads to new constructions on new areas and increasing urban density, and arising of a construction approach which ignores energy and cost efficient building designs. Since urban texture has a direct effect on a building's benefit from sun and wind depending on the space between buildings and their relative positions which together create the texture, it also affects buildings' energy and economic performances. Therefore, designing residential buildings and urban textures which do not only meet sheltering needs - one of the basic needs of people - but also are healthy, high quality and use energy resources effectively becomes even more important for Turkey. For this purpose, this study intends to evaluate building performance in urban texture alternatives developed for Istanbul where new urban textures are being developed rapidly in order to determine the impact of urban textures on the energy and economic performance of buildings.

\section{Methodology}

This study suggests an approach to evaluate the impacts of urban texture alternatives developed for Istanbul with regard to energy and cost efficiency on building energy performance. The following steps are taken for the suggested approach:

- Defining design parameters for urban textures,

- Defining design parameters for the reference building,

- Developing urban texture alternatives based on the defined design parameters,

- Evaluating the impacts of developed urban texture alternatives on building performance in terms of energy and cost efficiency.

\subsection{Defining design parameters for urban textures}

In this study, various urban textures were developed based on the aspect ratio commonly used to characterize urban textures. The impacts of urban texture alternatives on building performance were analyzed in terms of energy and cost efficiency. 0.50, 1.00 and 2.00 were accepted as $\mathrm{H} / \mathrm{W}$ values to create different urban textures. To determine street widths for the three different $\mathrm{H} / \mathrm{W}$ values used in the study, a 5-storey residential building among many types of residential buildings with different heights in Istanbul was selected. With this, the aim was to evaluate energy and economic performances of the buildings depending on different orientations of the buildings in the urban textures. Building energy and economic performance analyses were carried out for the reference residential building in each urban texture.

\subsection{Defining design parameters for the reference building}

In order to achieve general acceptance to define the design parameters for the reference building in the urban texture, residential building types built by TOKI (Housing Development Administration of Turkey), which plays an important role in the construction of residential buildings in Turkey, were researched and assessed. Based on the research, housing unit with floor area of $100 \mathrm{~m}^{2}$ was chosen. Building, occupant and active building systems information/values which were used to determine the reference residential building are shown in Table 1.

Table 1. Characteristics of the reference residential building

\begin{tabular}{|c|c|}
\hline Parameter & Value \\
\hline No. of floors & 5 \\
\hline Floor to floor height & $3.00 \mathrm{~m}$ \\
\hline Building height & $15 \mathrm{~m}$ \\
\hline Floor area & $400 \mathrm{~m}^{2}$ \\
\hline $\begin{array}{l}\text { Building length/building depth } \\
\text { in the plan }\end{array}$ & 1.00 (square plan) \\
\hline $\begin{array}{l}\text { A/V ratio (total external } \\
\text { surface / building volume) }\end{array}$ & 0.2 \\
\hline $\begin{array}{l}\text { Total transparent area /total } \\
\text { facade area }\end{array}$ & $\begin{array}{l}30 \% \text { (north, south, east, } \\
\text { west) }\end{array}$ \\
\hline Constant air change rate & $0.5 \mathrm{ac} / \mathrm{h}$ \\
\hline Occupant density & $0.04 \mathrm{~m}^{2} /$ person \\
\hline Occupant clothing type & $\begin{array}{l}1 \text { clo (heating period), } 0.5 \\
\text { clo (cooling period) }\end{array}$ \\
\hline Heating set point & $\begin{array}{l}20^{\circ} \mathrm{C}(07: 00-23: 00), 13^{\circ} \mathrm{C} \\
\text { (other hours) }\end{array}$ \\
\hline Cooling set point & $\begin{array}{l}26^{\circ} \mathrm{C}(07: 00-23: 00), 32^{\circ} \mathrm{C} \\
\text { (other hours) }\end{array}$ \\
\hline Minimum fresh air & $10 \mathrm{l} / \mathrm{s}$ \\
\hline Heating system & $\begin{array}{l}\text { penthouse condensing boiler } \\
\text { type central system, energy } \\
\text { type natural gas }\end{array}$ \\
\hline Cooling system & $\begin{array}{l}\text { COP } 4.50 \text {, energy type } \\
\text { electric energy }\end{array}$ \\
\hline
\end{tabular}

While developing the details for the layering of building envelope of the reference building, the building envelope sections which are commonly used in the existing mass housing projects were used and the total heat transfer coefficient values $\left(\mathrm{U}, \mathrm{W} / \mathrm{m}^{2} \mathrm{~K}\right)$ of the opaque and transparent components of the building envelope comply with the limit values set for Istanbul in TS 825 (2013) $\left(\mathrm{U}_{\text {wall }}: 0.57 \mathrm{~W} / \mathrm{m}^{2} \mathrm{~K}, \mathrm{U}_{\mathrm{g}_{\text {floor }}}: 0.53 \mathrm{~W} / \mathrm{m}^{2} \mathrm{~K}\right.$, 
$\left.\mathrm{U}_{\text {roof }}: 0.38 \mathrm{~W} / \mathrm{m}^{2} \mathrm{~K}, \mathrm{U}_{\text {window }}: 1.40 \mathrm{~W} / \mathrm{m}^{2} \mathrm{~K}\right)$. There are four housing units on each floor of the building and each housing unit was accepted as a single conditioned zone (area which is heated/cooled) (Fig. 1).

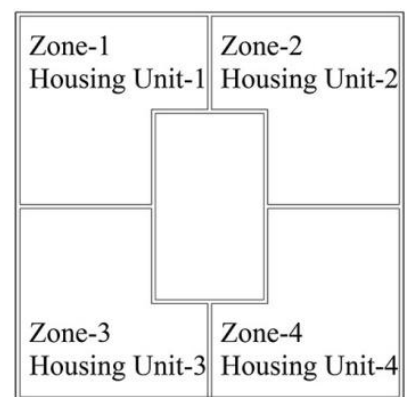

Fig. 1. Conditioned zone areas of the reference building.

\subsection{Developing urban texture alternatives based on the defined design parameters}

Urban texture alternatives based on the defined design parameters were developed with different $\mathrm{H} / \mathrm{W}$ values. In order to evaluate energy performances of reference residential buildings in urban textures developed, it is assumed that the urban textures consist of detached buildings (minimum $9(3 \times 3))$ in a study area of approximately $30,000 \mathrm{~m}^{2}$. The number of buildings in the urban textures varies depending on the $\mathrm{H} / \mathrm{W}$ ratios of the alternatives. Orientation of an urban texture changes at $45^{\circ}$ angles depending on the reference residential building defined in each urban texture and intersecting reference streets at the location of the reference residential building (Fig. 2).

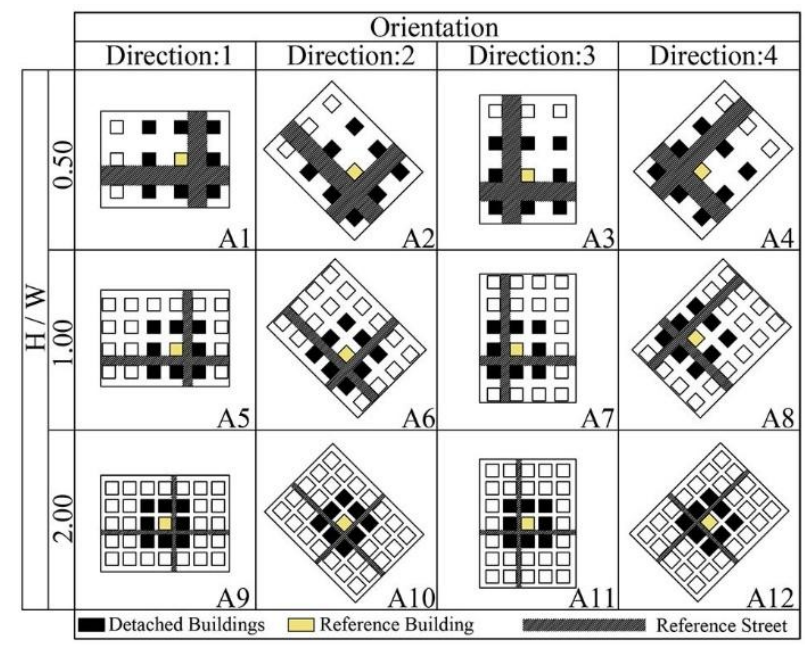

Fig. 2. Developed urban texture alternatives.

\subsection{Evaluating the impacts of developed urban texture alternatives on building performance in terms of energy and cost efficiency}

Energy analyses to calculate final energy consumption and life cycle cost analyses integrated to energy analyses were carried out to evaluate the impacts of developed urban texture alternatives on building performance in terms of energy and cost efficiency.
Final energy consumptions of the reference residential building in the urban textures developed in this study were calculated using DesignBuilder simulation program, the comprehensive interface of the EnergyPlus dynamic thermal simulation engine. Heating energy consumption (kWh/a), cooling energy consumption $(\mathrm{kWh} / \mathrm{a})$, lighting energy consumption $(\mathrm{kWh} / \mathrm{a})$, and total (heating+cooling+lighting) energy consumption $(\mathrm{kWh} / \mathrm{a})$ were calculated within the scope of the final energy consumption.

In order to compare the sum of the future cash flows concerning the urban texture alternatives (e.g. energy cost savings that occur during the lifetime of a reference residential building), LCC analysis takes into account "time value of money" by discounting the future expenditures to the present day equivalence. Thus, a central feature of LCC is the application of net present value (NPV) which is accepted as a standard measure used to determine and compare the cost effectiveness of the developed urban texture alternatives. In this study, initial investment costs $(€)$ and operational costs $(€)$ were included in the life cycle cost analyses carried out as part of the energy analyses. However, since initial investment costs of the reference residential building in all urban texture alternatives were the same, only operational costs were considered in life cycle cost calculations. For the calculation of the operational costs, only the energy costs were taken into consideration because sufficient data related to the maintenance and repair costs could not be obtained. The annual energy consumption based on the fuel type and the unit costs based on the fuel type are considered in order to determine the energy costs of the reference residential building in the urban texture alternatives handled and the following equation was used to calculate such costs:

$$
C_{\text {energy }}=\sum E_{\text {cons,fuel }} \times C_{\mathrm{u}, \text { fuel }}
$$

where $C_{\text {energy }}$ is the energy cost $(€ / \mathrm{a}), E_{\text {cons,fuel }}$ is the energy consumption per fuel type $(\mathrm{kWh} / \mathrm{a})$ and $C_{u \text {,fuel }}$ is the unit cost per fuel type $(€ / \mathrm{kWh})$.

Based on the energy analyses carried out in the study, regarding energy consumption with each fuel type; annual final energy consumptions for natural gas (heating) and electricity (cooling + lighting) were taken into account. The price of electricity according to the residential rate tariff applied by Turkish Electricity Distribution Corporation (TEDC) is $0.073 € / \mathrm{kwh}$ [14]. Unit price for natural gas is $0.019 € / \mathrm{kWh}$ for Istanbul [15].

Operational cost is the cost which will be repeated during the life cycle of the reference residential building. Therefore, the annual stream of the benefits related to the annual energy savings are discounted to the present values (for the year 2018). The NPV of energy retrofit strategies $(€)$ is calculated using the following equation:

$$
N P V=\sum_{t=0}^{T} c f_{t}(1+i)^{-t}
$$

where $c f_{t}$ is the cash flow at time $\mathrm{t}$ (positive for earnings, negative for expenditures), $T$ is the calculation period (years) and $i$ is the discount rate. 
Among economic variables which are required for economic performance analyses, discount rate was accepted as $3 \%$, calculation period was accepted as 30 years [16] and the start date for calculation was 2018. In this study, applicable taxes were neglected when calculating costs and the exchange rate announced by the Central Bank of the Republic of Turkey (CBRT) was used as the current exchange rate [17].

Energy and cost analyses were carried out separately for the reference residential building in each urban texture. Values found in the analyses were used to compare the level of impact of urban textures on building performance and the alternative which provides the lowest life cycle cost was determined as the energy and cost efficient alternative.

\section{Results}

As a result of the evaluating of the urban texture alternatives in terms of energy and cost efficiency; A3 (direction:3), A7 (direction:3) and A9 (direction:1) were determined as the energy and cost efficient alternatives for $\mathrm{H} / \mathrm{W}: 0.50, \mathrm{H} / \mathrm{W}: 1.00$ and $\mathrm{H} / \mathrm{W}: 2.00$ respectively (Figs.3-5).

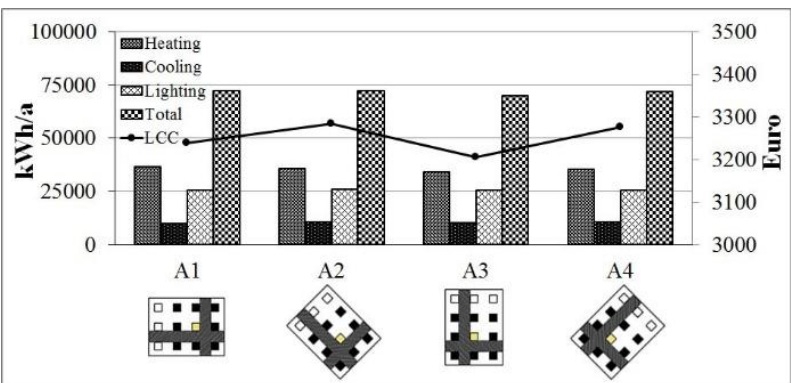

Fig. 3. Energy and cost analyses results of reference building in the urban texture alternatives developed for $\mathrm{H} / \mathrm{W}: 0.50$.

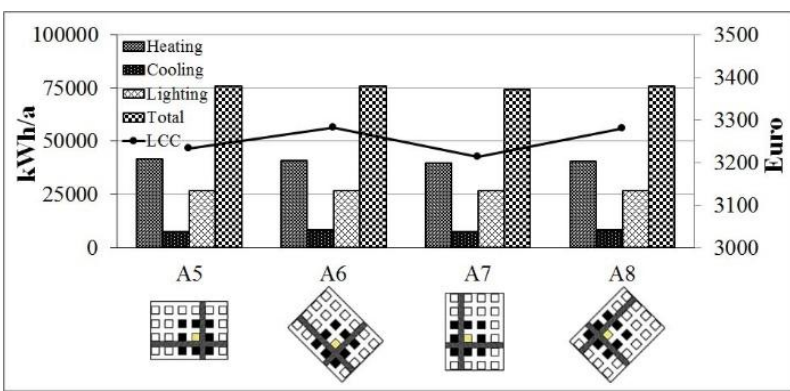

Fig. 4. Energy and cost analyses results of reference building in the urban texture alternatives developed for $\mathrm{H} / \mathrm{W}: 1.00$.

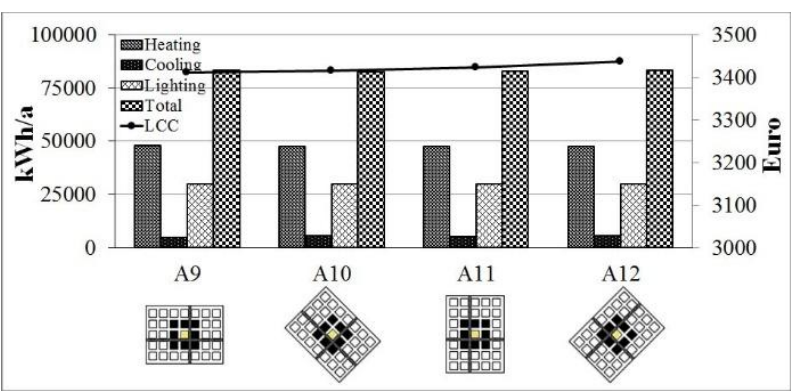

Fig. 5. Energy and cost analyses results of reference building in the urban texture alternatives developed for $\mathrm{H} / \mathrm{W}: 2.00$.
According to the energy analyses results as seen in Fig.3; for the urban texture alternatives with $\mathrm{H} / \mathrm{W}$ : 0.50 , when the alternative A3 was compared with the alternative A2 (direction:2) which gave the lowest results for energy and economic performance, 4\% decrease in annual heating energy consumption, $6 \%$ decrease in annual cooling energy consumption were observed and only a neglectable change was found in the annual lighting energy consumption. Annual total (heating + cooling + lighting) energy consumption decreased by $3 \%$ when it was compared to $\mathrm{A} 2$. According to the cost analyses results; for the urban texture alternatives with $\mathrm{H} / \mathrm{W}: 0.50$, when the alternative A3 was compared with the alternative A2 (direction:2), a decrease of $2 \%$ was achieved in the annual operational cost and life cycle cost.

According to the energy analyses results as seen in Fig.4; for the urban texture alternatives with $\mathrm{H} / \mathrm{W}: 1.00$, when the alternative A7 was compared with the alternative A6 (direction:2) which gave the lowest results for energy and economic performance, 2\% decrease in annual heating energy consumption, $7 \%$ decrease in annual cooling energy consumption, $1 \%$ decrease in lighting energy consumption and $2 \%$ decrease in annual total (heating + cooling + lighting) energy consumption were found. According to the cost analyses results; for the urban texture alternatives with $\mathrm{H} / \mathrm{W}: 1.00$, when the alternative A7 was compared with the alternative A6 (direction:2), a decrease of $2 \%$ was achieved in the annual operational cost and life cycle cost.

According to the energy analyses results as seen in Fig.5; for the urban texture alternatives with $\mathrm{H} / \mathrm{W}: 2.00$, when the alternative A9 was compared with the alternative A12 (direction:4) which gave the lowest results for energy and economic performance, $1 \%$ increase in annual heating and lighting energy consumption, $12 \%$ decrease in annual cooling energy consumption were observed and only a neglectable change was found in the annual total (heating + cooling + lighting) energy consumption. According to the cost analyses results; for the urban texture alternatives with H/W: 2.00, when the alternative A9 was compared with the alternative $\mathrm{A} 12$ (direction:4), a decrease of 1\% was achieved in the annual operational cost and life cycle cost.

\section{Conclusion}

The world's population is increasingly urbanised and increasing energy and environmental problems caused by rapid urbanization has become a driving force behind the need to adopt energy efficient paradigms and implement sustainability measures. The most important parameter which affects energy and economic performance of buildings with critical importance is the urban texture which can last for longer years without any major change. Therefore, inclusion of the effects of urban microclimates in all evaluations of building energy and economic performance, in other words determination of level of effect of urban textures which 
are directly related with a building's energy and economic performance is critical to make correct decisions for sustainable, energy efficient building and urban texture design. This study aims to develop a model with which urban texture-building interaction can be analysed to design sustainable, energy and cost efficient urban textures. The effect of the design parameters of urban texture (building height/street width, street and façade orientation) was analysed using the alternatives defined for this purpose for Istanbul representing temperate-humid climatic region and the findings are compared and presented.

The findings of the study demonstrates that since the heating period is longer than the cooling period in Istanbul representing temperate-humid climatic region, heating energy consumption constitutes important part of the total energy consumption of the reference residential building in the urban texture alternatives. On the other hand, since the unit price of electricity consumed for cooling and lighting is much higher than the unit price of natural gas consumed for heating, cooling and lighting energy costs have more effect on the life cycle costs (covers a period of 30 years of operation) of the reference residential building defined in the urban texture alternatives.

Using the findings of this study it is possible to make a projection about the change of the level of the impact of different urban textures on the energy and economic performance of the reference residential building used widely in Turkey. However, the number of analyses carried out within the context of this study which was only limited should be much higher to achieve an acceptable general conclusion. Especially in this period in which urban transformation projects continue without slowing down in the country in general, urban textures should be designed taking energy and cost efficient building approach into account, country resources should be used efficiently and maximum benefit should be obtained for decision makers.

This study is supported by a grant from the Scientific Research Projects Unit of Istanbul Technical University under the Scientific Research and Development Support Program (Project No: 39956).

\section{References}

1. K.C. Seto, B. Güneralp, L.R. Hutyra, Proc. Natl. Acad. Sci. U. S. A. 109, 16083 (2012).

2. UN. (2014).

3. UN-Habitat. (2012).

4. IEA. (2013).

5. C. Ratti, D. Raydan, K. Steemers, Energy Build, 35, 49 (2003).

6. C. Ratti, N. Bakker, K. Steemers, Eergy Build, 37, 762 (2005).

7. IEA. (2011).

8. Oke, T.R., Atmosphere, 14, 268 (1976).
9. Sanaieian H. Tenpierik M. Linden,K. Seraj, F.M. Shemrani, S.M.M., Renew Sustain Energy Rev, 38, 551 (2014)

10. Jamei E. Rajagopalan P. Seyedmahmoudian M. Jamei Y., Renew Sustain Energy Rev, 54, 1002 (2016)

11. F. Ali-Toudert, The Seventh International Conference on Urban Climate, 2009, Japan.

12. J. Strømann-Andersen, P.A. Sattrup, Energy Build, 43, 2011 (2011).

13. IZODER (2016). https://www.izoder.org.tr/dosya lar/ haberler/Turkiye-U-degerleri-haritasi-raporu-2016Turkce.pdf [accessed : 10.02.2018]

14. TEDC. (2018). http://eskiweb.epdk.org.tr/TR/ Mevzuat $/ \mathrm{H}=0 ; \mathrm{MT}=6 \mathrm{~L} ; \mathrm{G}=159 ; \mathrm{AG}=1 ; \mathrm{S}=1 ; \mathrm{SNO}=0 ; \mathrm{SKY}=$ $\underline{0}$; [accessed :10.02.2018]

15. IGDAS. (2018). https://www.igdas.istanbul/serbesttuketici-satis/ [accessed :10.02.2018]

16. EC. (2012).

17. CBRT. (2018). http://www.tcmb.gov.tr/kurlar/2018 $\underline{\text { 02/02022018.xml [accessed :10.02.2018] }}$ 